\title{
An unusual case of "giant cell arteritis"
}

\author{
J Lim, R Ramachandran, R Madhok, H Capell
}

Ann Rheum Dis 2004;63:1347-1348. doi: 10.1136/ard.2003.017244

$\mathrm{C}$ holesterol emboli syndrome (CES) can be confused with a small vessel vasculitis but it is unusual for it to be mistaken for giant cell arteritis. We report a patient with temporal headaches, transient visual loss, and raised inflammatory indices, which led to an initial diagnosis of giant cell arteritis, but in whom CES was the eventual explanation.

\section{CASE REPORT}

A 64 year old woman with treated hypertension who smoked was referred with a 1 year history of left sided temporal headaches and pain in the proximal lower limbs. The headaches were intermittent but were increasing in frequency and intensity. She also described two episodes of blurred vision of short duration in the left eye. There were no other associated neurological symptoms. She gave a history of Raynaud's phenomenon in both hands and worsening activities of daily living limited by fatigue.

She was overweight with a body mass index of $27 \mathrm{~kg} / \mathrm{m}^{2}$; there were no mucocutaneous abnormalities. The temporal arteries were not palpable and a fundoscopic examination was normal. All peripheral pulses were present and there were no nailfold capillary changes. She had no tender or swollen joints; there was functional range of movement in axial and peripheral joints.

Laboratory investigations showed haemoglobin of $127 \mathrm{~g} / \mathrm{l}$, a white cell count of $10.7 \times 10^{9} / 1$ with a normal differential, and $625 \times 10^{9} / 1$ platelets. The erythrocyte sedimentation rate (ESR) was $60 \mathrm{~mm} / \mathrm{lst} \mathrm{h}$ and $\mathrm{C}$ reactive protein (CRP) $290 \mathrm{mg} / \mathrm{l}$. She had a serum urea and creatinine of $5.5 \mathrm{mmol} / \mathrm{l}$ and $96 \mu \mathrm{mol} / \mathrm{l}$, respectively, with normal urine microscopy. The liver enzymes were not raised. Rheumatoid and antinuclear factor were absent.

Based on her symptoms and raised inflammatory indices, a provisional diagnosis of temporal arteritis was made and treatment was started with prednisolone $50 \mathrm{mg}$ daily. A left temporal artery biopsy showed atherosclerotic change without evidence of granulomatous inflammation. This negative result was attributed to sampling error.

She continued to have multiple episodes of transient monocular visual loss which were highly suggestive of amaurosis fugax. She had also developed more troublesome acrocyanosis, livedo reticularis, and had a blood pressure of 190/83. The neurological examination was normal and there were no audible carotid bruits. Urine analysis remained negative, with normal renal function and inflammatory indices, but the total cholesterol was raised at $7.4 \mathrm{mmol} / \mathrm{l}$. Her ECG did not suggest a rhythm abnormality. Formal fundoscopic examination showed a cholesterol crystal lodged in a vessel with background atherosclerotic change (fig 1). Carotid Doppler ultrasonography showed echolucent atherosclerotic plaques with a lumen diameter of $2 \mathrm{~mm}$, while trans-oesophageal echocardiography did not show any mural thrombus or plaques in the aortic arch. A statin and aspirin were added to her drug treatment. Prednisolone was tapered over 2 weeks and stopped. When reviewed she denied further visual symptoms or other evidence of systemic emboli.

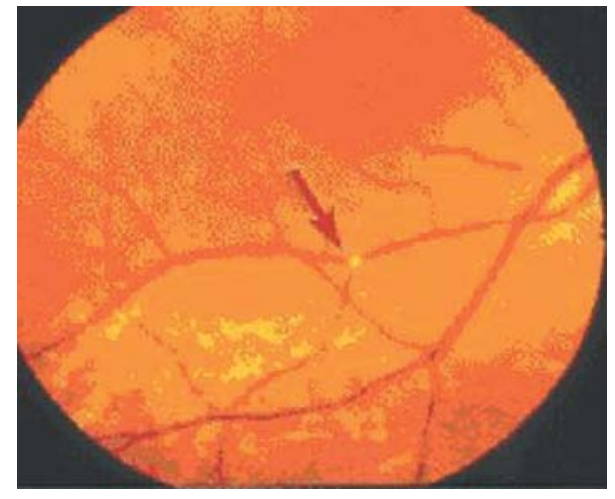

Figure 1 Retinal photograph showing a cholesterol crystal lodged in the small vessel of the retina (arrow).

\section{DISCUSSION}

CES arises because of distal showering of cholesterol crystals into the circulation from atheromatous plaques. ${ }^{1}$ Panum first described this phenomenon in 1862. ${ }^{2}$ The presence of an aortic aneurysm, angioplasty, major vessel surgery, and use of thrombolytic and anticoagulating agents further increases the likelihood of CES. ${ }^{3-5}$

Our patient fulfilled three of the five classification criteria for giant cell arteritis formulated by the American College of Rheumatology. ${ }^{6}$ Furthermore, she had visual symptoms, myalgia, and a raised acute phase response, which further supported our diagnosis. But the partial response to corticosteroids, worsening visual symptoms, emergence of livedo reticularis, and acrocyanosis suggested an alternative explanation. Fundoscopic evidence of cholesterol emboli confirmed the occurrence of CES.

Pseudovasculitis is sometimes used to describe the occurrence of fever, myalgia, leucocytosis, and raised ESR and CRP due to cholesterol emboli. The acute phase response is thought to arise from the inflammation provoked by the presence of cholesterol emboli in the vessel lumen and may explain the partial response to corticosteroids. No treatment has been proved to improve the outcome of CES, though statins have the theoretical benefit of plaque stabilisation. ${ }^{7}$

Interestingly, there is only one other case report of CES masquerading as giant cell arteritis (PubMed search $\left.{ }^{8}\right)$. This is surprising given the similarity in the signs and symptoms of the two conditions and that both occur more frequently in those over the age of 50. Our case serves as reminder that not all older patients with headaches, myalgia, visual symptoms, and high ESR have giant cell arteritis. CES should be considered in those with a negative biopsy, a poor clinical response to corticosteroids, and risk factors for atherosclerosis.

\section{Authors' affiliations \\ J Lim, R Ramachandran, R Madhok, H Capell, Centre of Rheumatic Diseases, Glasgow Royal Infirmary, Glasgow, Scotland, UK}


Correspondence to: Dr R Madhok, Centre of Rheumatic Diseases, Ward 14/15, Glasgow Royal Infirmary, Castle Street, Glasgow G4 OSF, Scotland, UK; gcl103@clinmed.gla.ac.uk

Accepted 6 December 2003

\section{REFERENCES}

1 Creager MA, Libby P. Peripheral arterial disease. In: Braunwald E, Douglas P, Libby P, eds. Heart disease. 6th ed. Philadelphia: Saunders, 2001:1457-8.

2 Panum PL. Experimentelle Bietrage zur Lehre von der Embolie. Virchows Arch Cell Pathol 1862;25:308-10.
3 Dupont PJ, Lightstone L, Clutterbuck EJ, Gaskin G, Pusey CD, Cook T, et al. Lesson of the week: Cholesterol emboli syndrome. BMJ 2000;321:1065-7. 4 Hyman BT, Landas SK, Ashman RF, Schelper RL, Robinson RA. Warfarinrelated purple toe syndrome and cholesterol microembolization. Am J Med 1987:82:1233-7.

5 Geraets DR, Hoehms JD, Burke TG, Grover-McKay M. Thrombolyticassociated cholesterol emboli syndrome: case report and literature review. Pharmacotherapy 1995;15:441-50.

6 Hunder GG, Bloch DA, Michel BA, Stevens MB, Arend WP, Calabrese LH, et al. American College of Rheumatology 1990 criteria for the classification of giant cell arteritis. Arthritis Rheum 1990;33:1122-8.

7 Dahlberg PJ, Frecentese DF, Cogbill TH. Cholesterol embolism: experience with 22 histologically proven cases. Surgery 1989;105:737-46.

8 Jacobson DM. Systemic cholesterol microembolization syndrome masquerading as giant cell arteritis. Surv Opthalmol 1991;36:23-7.

\section{Visceral leishmaniasis resembling systemic lupus erythematosus}

\section{P V Voulgari, G A Pappas, E N Liberopoulos, M Elisaf, F N Skopouli, A A Drosos}

S ystemic lupus erythematosus (SLE) is a chronic autoimmune disease of unknown aetiology. B cell hyperactivity with production of multiple autoantibodies is the hallmark of the disease. ${ }^{1}$ On the other hand, such polyclonal $\mathrm{B}$ cell activation may occur in chronic infectious diseases. In this report we present a patient with visceral leishmaniasis who was diagnosed as having SLE and we discuss the clinical and laboratory findings which may discriminate between these two entities.

\section{CASE REPORT}

A 50 year old man presented in October 2001 with arthralgias, fatigue, weight loss, and low grade fever. Laboratory evaluation revealed haemoglobin $110 \mathrm{~g} / \mathrm{l}$, white blood cells $3.9 \times 10^{9} / 1$ with normal differential count, platelets $90 \times 10^{9} / 1$, and erythrocyte sedimentation rate (ESR) $50 \mathrm{~mm} /$ lst h.

He was admitted to the hospital where physical examination disclosed mild splenomegaly. A laboratory investigation confirmed anaemia, leucopenia, and thrombocytopenia, increased ESR and $\mathrm{C}$ reactive protein (CRP) (table 1). Renal, liver and thyroid function tests, as well as urine analysis were within normal limits or negative. Serum electrophoresis showed moderate diffuse hypergammaglobulinaemia with no monoclonal bands. A stool specimen for occult blood was negative. Repeated blood, urine, throat, and bone marrow cultures were negative. Serological tests for viral hepatitis B and C, cytomegalovirus, Epstein-Barr virus, and human immunodeficiency virus, as well as for toxoplasma and brucella infections were negative. Immunological tests showed positive antinuclear antibodies (ANA) at a titre of 1/1280 with a fine speckled pattern, positive $\operatorname{IgM}$ rheumatoid factor at a titre of $1 / 640$, positive anti-Sm antibodies, positive Venereal Disease Research Laboratory (VDRL) test and positive lupus anticoagulant test (table 1). A chest radiograph was normal and a purified protein derivative test was negative. Finally, bone marrow biopsy showed no abnormalities. A diagnosis of SLE was made.

Two months later, the patient experienced high spike fever, fatigue, and weight loss. He was treated with small doses of steroids without improvement and he was admitted for further evaluation. Physical examination showed a body temperature of $39^{\circ} \mathrm{C}$. The patient was sweating, anxious, and pallid. The rest of physical examination disclosed moderate splenomegaly. A computed tomography scan of the abdomen confirmed the presence of splenomegaly. Laboratory and immunological tests were similar to those done previously (table 1). However, a high titre of antibodies directed against Leishmania donovani was detected (1/1280 by immunofluorescence assay). A repeated bone marrow biopsy disclosed the presence of parasites in the macrophages (fig 1). Sodium antimony gluconate was given intramuscularly for 4 weeks, with excellent results.

\section{DISCUSSION}

The haematological abnormalities of SLE include haemolytic anaemia, leucopenia or lymphopenia, and thrombocytopenia, due to the presence of autoantibodies directed against erythrocytes, leucocytes, and platelets. ${ }^{1}$ The diagnosis of SLE requires four or more of the American College of Rheumatology criteria. ${ }^{2}$ In our patient the diagnosis of SLE was based on the following criteria: arthralgias, haematological abnormalities, positive ANA, and positive VDRL and anti-Sm antibodies. However, this patient also had splenomegaly and high titres of CRP. Splenomegaly is not a common sign of SLE, unless there is lymphoma development or concurrent infection. High titres of CRP are not a common laboratory finding in SLE, unless a concurrent infection occurs. However, high titres of CRP in lupus have been associated with symmetrical polyarthritis and the presence of pleurisy. ${ }^{3}$

Table 1 Laboratory and immunological features

\begin{tabular}{lll}
\hline Variables & October 2001 & February 2002 \\
\hline Haemoglobin (g/l) & 110 & 105 \\
White blood cells $\left(\times 10^{9} / \mathrm{I}\right)$ & 3.9 & 3.65 \\
Platelets $\left(\times 10^{9} / \mathrm{I}\right)$ & 90 & 75 \\
ESR (mm/1 st h) & 50 & 65 \\
$\mathrm{C}$ reactive protein $(\mathrm{mg} / \mathrm{l})$ & 56 & 75 \\
Antinuclear antibodies (titre) & $1 / 1280$ & $1 / 1280$ \\
IgM rheumatoid factor (titre) & $1 / 640$ & $1 / 640$ \\
Anti-Sm antibodies & Positive & Negative \\
VDRL test & Positive & Not done \\
Lupus anticoagulant & Positive & Not done \\
Direct Coombs test & Positive & Negative \\
\hline
\end{tabular}

VDRL, Venereal Disease Research Laboratory 


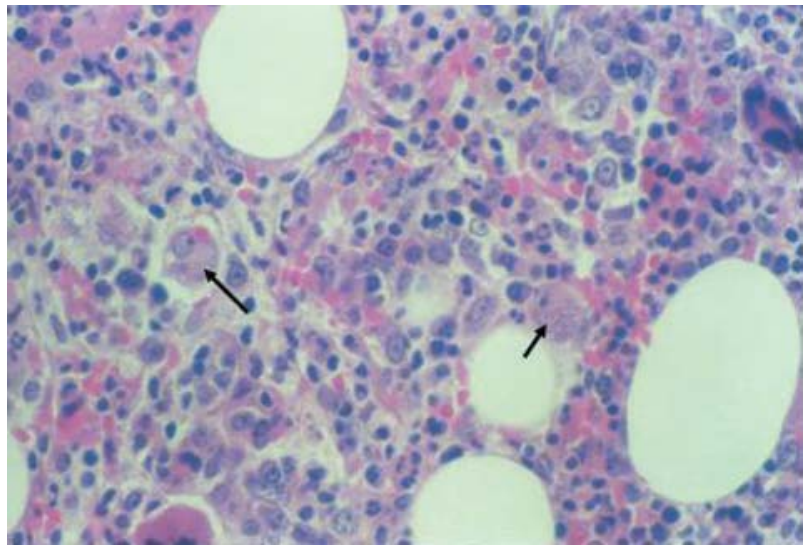

Figure 1 Bone marrow biopsy. Leishmania parasites are phagocytosed by macrophages (arrows). Haematoxylin and eosin $\times 400$.

On the other hand, splenomegaly is a common finding in chronic infections, and especially in parasitic ones. Visceral leishmaniasis is caused by Leishmania donovani. It is characterised by fever, sweating, cytopenias and may be associated with many immunological abnormalities. Haematological abnormalities expressed as leucopenia, thrombocytopenia, or anaemia are mainly due to splenomegaly and hypersplenism.

Leishmania donovani is an intracellular parasite which attaches to macrophage receptors, and is phagocytosed and multiplies. In addition, Leishmania donovani infection induces a non-specific, as well as a specific antibody production, much of which is probably due to the parasite-released substances, which act as B cell mitogens. ${ }^{45}$ As a consequence of the B cell hyperactivity, Leishmania donovani may cause hypergammaglobulinaemia and the production of autoantibodies such as ANA, and others. ${ }^{6}$ On the other hand, the prolonged saturation of the reticuloendothelial system infected by parasites contributes to organomegaly and mainly to splenomegaly, causing cytopenias.

We conclude that:

- All patients with positive ANA do not have SLE

- Splenomegaly is not a common sign in patients with SLE

- High titres of CRP are not a common laboratory finding in lupus patients and may discriminate SLE from infections

- Visceral leismhaniasis may present with cytopenias and the production of autoantibodies mimicking SLE.

\section{Authors' affiliations}

P V Voulgari, G A Pappas, E N Liberopoulos, M Elisaf, A A Drosos, Department of Internal Medicine, Medical School, University of loannina, Greece

F N Skopouli, Department of Nutrition and Dietetics, University of Harokopion, Athens, Greece

Correspondence to: Professor A A Drosos, Department of Internal Medicine, Medical School, University of loannina, 45110 loannina, Greece; adrosos@cc.voi.gr

Accepted 18 November 2003

\section{REFERENCES}

1 Mohan C, Adams S, Stanic V, Datta SK. Nucleosome: a major immunogen for pathogenic autoantibody-inducing $T$ cells of lupus. J Exp Med 1993; 177:1368-81.

2 Tan EM, Cohen AS, Fries JF, Masi AT, McShane DJ, Rothfield NF, et al. The 1982 revised criteria for the classification of systemic lupus erythematosus. Arthritis Rheum 1982;25:1271-7.

3 Moutsopoulos HM, Mavridis AK, Acritidis NC, Avgerinos PC. High $\mathrm{C}$-reactive protein response in lupus polyarthritis. Clin Exp Rheumatol 1983; 1:53-5.

4 Reiner SL, Locksley RM. The regulation of immunity to Leishmania major. Annu Rev Immunol 1995;13:151-77.

5 Bogdan C, Rollinghoff M. How do protozoan parasites survive inside macrophages? Parasitol Today 1999;15:22-8.

6 Liberopoulos E, Pappas G, Kostoula A, Drosos A, Tsianos E, Elisaf M. Spectrum of autoimmunity and dysproteinemia in patients with visceral leishmaniasis. Clin Microbiol Infect 2003;9(suppl 1):417.

\section{Neurovascular mechanisms as a possible cause of remission of rheumatoid arthritis in hemiparetic limbs}

\section{G Keyszer, Th Langer, M Kornhuber, B Taute, G Horneff}

I: patients with rheumatoid arthritis (RA), ischaemic stroke frequently leads to an unexplained remission of the arthritis in the paretic limb. Here we present two cases which suggest that neurovascular mechanisms contribute to the asymmetry of inflammation by impairing the microcirculation in the paretic extremity.

\section{CASE REPORTS}

A 47 year old man developed RA in 1988. In 1990, he had an apoplectic insult, resulting in a complete, left sided hemiplegia. The right hand had a marked ulnar drift of the metacarpophalangeal (MCP) joints and an inflamed wrist with impaired motion, whereas the left hand showed no inflammation or deformity. An $x$ ray analysis of the right hand demonstrated carpal ankylosis and subluxation and erosion of all MCP joints. The left hand showed no erosive changes (fig 1A). Thermal imaging indicated marked temperature differences between both hands, most obvious at the wrists (fig 1B). Duplex sonography measured no detectable flow of the left radial artery. Electrophysiological investigation suggested demyelination that was slightly more pronounced on the paralytic side. The sympathetic skin response was negative.

The second case involved a 66 year old woman who had had RA since 1982. In 1988 she had an ischaemic stroke with right sided hemiparesis that later recovered, leaving merely somewhat diminished muscle strength and minor hyperaesthesia. The left wrist and all MCP joints had active arthritis, whereas on the right, only two MCP joints were inflamed. An $x$ ray analysis of the left hand disclosed carpal ankylosis, subluxation of all MCP joints, and erosions of all carpometacarpal (CMC), MCP, and proximal interphalangeal 

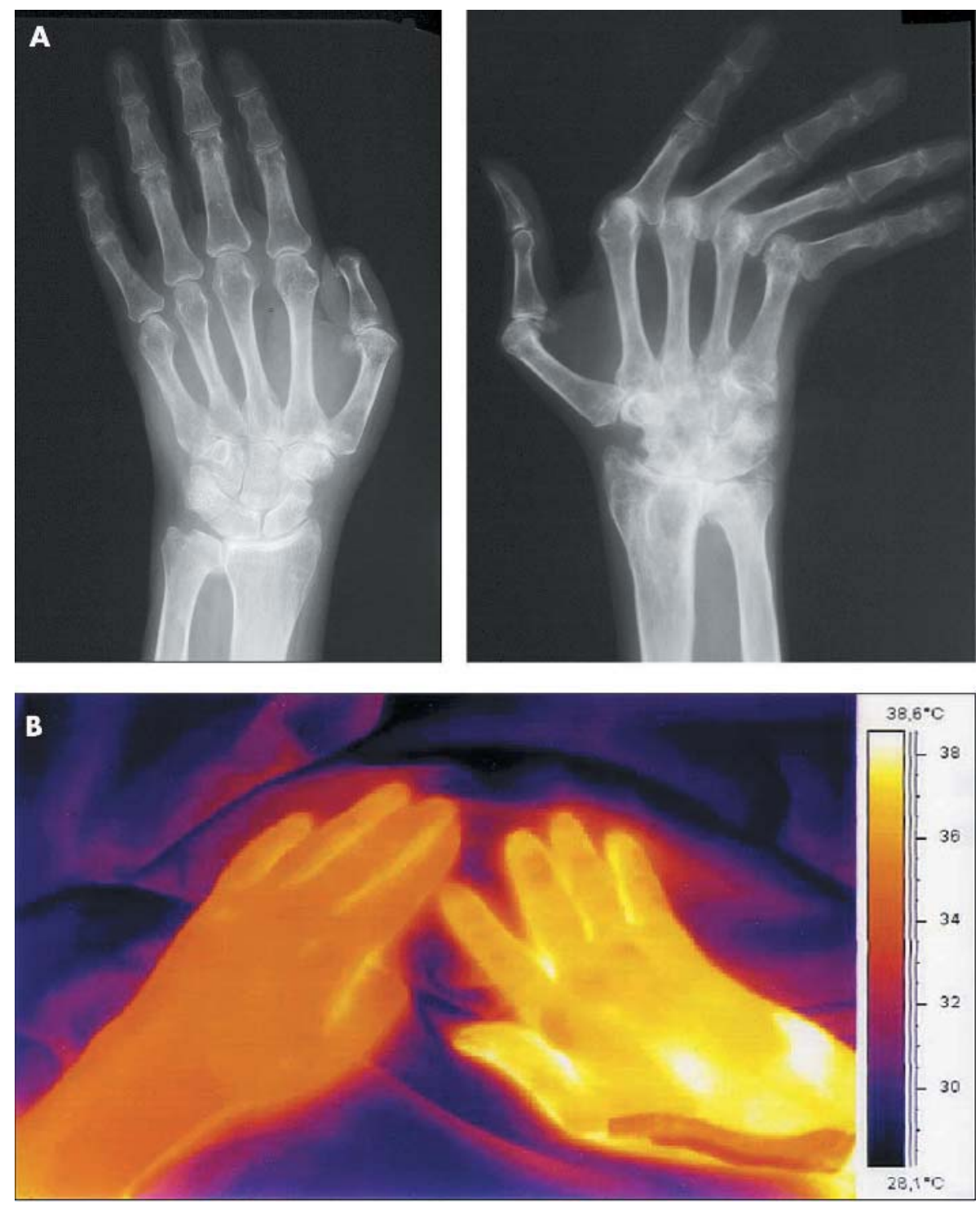

Figure 1 (A) A radiograph of the first patient, showing marked differences in the erosive changes between the paralytic left side and the non-paretic right side. The patient had had the tip of the right thumb amputated owing to a work related accident. (B) Thermographic image of both hands obtained by an AGEMA 550 thermographic camera (FLIR SYSTEMS, Portland, OR, USA).

(PIP) joints. The right hand showed erosions at one CMC joint and one PIP joint only. Thermal imaging showed a decreased skin temperature on the left wrist. However, the difference was not as marked as in the first patient. Interleukin 2, 4, 5, 10, tumour necrosis factor $\alpha$, and interferon $\gamma$ were determined in plasma on three consecutive days for each arm separately, but did not show differences between the two sides. Duplex sonography and electrophysiological investigation showed no asymmetry.

\section{DISCUSSION}

The mechanism by which RA is modified by hemiparesis is poorly understood. Our observations suggest a link between the severity of paralysis and the extent of the remission of arthritis. This agrees with biopsy findings of a mild arthritis in a knee joint after the restoration of the motor function of the paralysed leg. ${ }^{1}$

It has been suggested that the remission of arthritis after paralysis is due to the absence of mechanical factors. ${ }^{1}$ However, rheumatoid vasculitis and scleroderma can develop on the non-paretic side after hemiplegia, ${ }^{23}$ arguing against a mechanical link.

A role for the autonomic nervous system in inflammation has been discussed. ${ }^{4}$ Neurogenic peptides might contribute to the asymmetry of arthritis after stroke. ${ }^{5}$ In patients with RA with hemiplegia, there are no reports of different concentrations of neurogenic peptides on the two sides. In our patients, measurement of the sympathetic skin response did not suggest differences in autonomous innervation between the sides.

Another mechanism by which neurogenic factors might contribute to the asymmetry of arthritis is an impaired perfusion of the paretic limb. ${ }^{5}$ Our patients are the first in whom the skin temperature and the limb perfusion was assessed quantitatively. In our first case, no flow signal of the radial artery was detectable. The marked difference in skin temperature also indicates impaired microcirculation in both patients. Significantly, this phenomenon was most obvious in the patient with complete paralysis. Changes in skin temperature frequently occur after hemiplegic stroke. ${ }^{7}$ This 
may be accompanied by a reduced blood flow in the affected extremity. ${ }^{8}$ However, this phenomenon is not seen in all patients. ${ }^{7}$ This might explain why in rare cases the arthritis even flares after a stroke. ${ }^{5}$ So far, the influence of perfusion and temperature on the intensity of joint inflammation has not been investigated in detail. Hyperthermia and increased perfusion are usually seen as mere byproducts of inflammation. However, it is tempting to speculate that differences of temperature and perfusion might also actively contribute to the remission of arthritis after hemiplegia.

\section{Authors' affiliations}

G Keyszer, B Taute, University of Halle, Department of Internal Medicine, Ernst-Grube-Str 40, 06097 Halle/Saale, Germany Th Langer, Krankenhaus St Elisabeth und St Barbara, Department of Internal Medicine I, Mauerstr 5, 06110 Halle/Saale, Germany M Kornhuber, University of Halle, Department of Neurology, ErnstGrube-Str 40, 06097 Halle/Saale, Germany

G Horneff, University of Halle, Department of Paediatrics, Ernst-GrubeStr 40, 06097 Halle/Saale, Germany
Correspondence to: Dr G Keyszer; gernot.keyszer@medizin. uni-halle.de

Accepted 1 December 2003

\section{REFERENCES}

1 Thompson M, Bywaters EG. Unilateral rheumatoid arthritis following hemiplegia. Ann Rheum Dis 1962;21:370-7.

2 Dolan AL. Asymmetric rheumatoid vasculitis in a hemiplegic patient. Ann Rheum Dis 1995:54:532.

3 Sethi S, Sequeira W. Sparing effect of hemiplegia on scleroderma. Ann Rheum Dis 1990;49:999-1000.

4 Baerwald CG, Panayi GS. Neurohumoral mechanisms in rheumatoid arthritis Scand J Rheumatol 1997;26:1-3.

5 Pattrick M, Doherty M, Dieppe P. Unilateral exacerbation of rheumatoid arthritis by hemiparesis. Br J Rheumatol 1984;23:107-9.

6 Decaris E, Guingamp C, Chat M, Philippe L, Grillasca JP, Abid A, et al. Evidence for neurogenic transmission inducing degenerative cartilage damage distant from local inflammation. Arthritis Rheum 1999;42:1951-60.

7 Wanklyn P, Ilsley DW, Greenstein D, Hampton IF, Roper TA, Kester RC, et al. The cold hemiplegic arm. Stroke 1994;25:1765-70.

8 Adams WC, Imms FJ. Resting blood flow in the paretic and nonparetic lower legs of hemiplegic persons: relation to local skin temperature. Arch Phys Med Rehabil 1983;64:423-8.

\title{
Severe gouty arthritis refractory to anti-inflammatory drugs: treatment with anti-tumour necrosis factor $\alpha$ as a new therapeutic option
}

\author{
A K Tausche, K Richter, A Grässler, S Hänsel, B Roch, H E Schröder
}

Ann Rheum Dis 2004;63:1351-1352. doi: 10.1136/ard.2003.015743

W e report the case of a 53 year old man with a history of gouty arthritis extending over several years. He had had an acute kidney failure 2 years previously because of nephrolithiasis with urate calculi.

\section{CASE REPORT}

At the first consultation the patient had severe painful gouty arthritis (three to four attacks a week) of the joints of the big toes, the ankle joints, and different finger joints as well as in joints of the hands, shoulders, and knees. In addition to the polyarticular joint manifestation, multiple gouty tophi were present in the subcutaneous tissue (fig l).

The medical history of the patient showed he had arterial hypertension and hypertriglyceridaemia. He consumed 20-25 units of alcohol weekly. Standard treatment was impractical because the patient had developed incompatibility with allopurinol and benzbromarone, which manifested as diarrhoea and a generalised exanthema.

Laboratory tests showed a raised white blood cell count (WBC) of $9.4 \times 10^{9} /$; an erythrocyte sedimentation rate (ESR) $55 \mathrm{~mm} / \mathrm{lst} \mathrm{h}, \mathrm{C}$ reactive protein (CRP) $61.0 \mathrm{mg} / \mathrm{l}$, serum uric acid $580 \mu \mathrm{mol} / \mathrm{l}$. Transaminases were normal apart from a $\gamma$-glutamyltransferase of $282 \mathrm{U} / \mathrm{l}$. Clinical examination, including cardiovascular and respiratory systems, an electrocardiogram, and a chest radiograph were normal. Abdominal ultrasound was also normal apart from showing hepatomegaly. The radiographs of all symptomatic joints showed impressive signs of destructive gouty arthritis (fig 2).

Despite exhaustive treatment with colchicine, diclofenac, methylprednisolone, and opioids, the arthritis attacks did not improve considerably (table 1 ).

After obtaining the latest detailed information about the patient and his informed consent, treatment with etanercept
(Enbrel) $25 \mathrm{mg}$ subcutaneously twice weekly was started. As table 1 shows the frequency (gouty attacks per week) and the intensity (number of painful joints) of the gouty arthritis decreased considerably after four injections of etanercept. Laboratory tests showed a noticeable decrease of the inflammation, with WBC of $7.4 \times 10^{9} / \mathrm{l}$; ESR $6 \mathrm{~mm} / \mathrm{lst} \mathrm{h}$, CRP $6.1 \mathrm{mg} / \mathrm{l}$. During the anti-inflammatory treatment, antihyperuricaemic treatment with probenecid and urine alkalisers was maintained; the level of serum uric acid remained roughly the same.

Thus, treatment with the tumour necrosis factor $\alpha(\mathrm{TNF} \alpha)$ inhibitor etanercept in a patient with a complex gouty arthritis impressively reduced the clinical manifestations of gout, and uric acid depots were depleted generally.

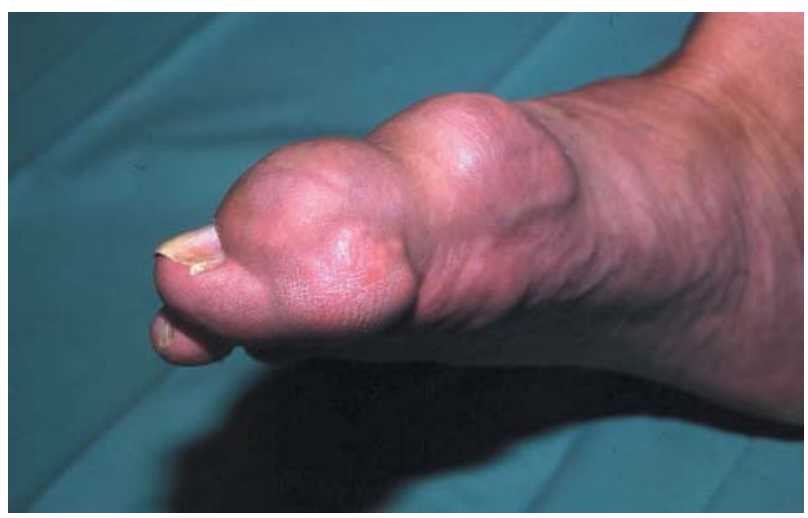

Figure 1 Clinical image of the right foot showing gouty arthritis with extreme swelling, erythema, and tophi. 
Table 1 Monitoring disease activity (clinical and laboratory findings) under different treatment courses

\begin{tabular}{|c|c|c|c|}
\hline Duration of treatment & $\begin{array}{l}5 \text { Months before anti-TNF } \alpha \\
\text { treatment }\end{array}$ & $\begin{array}{l}\text { After } 4 \text { th injection of } \\
\text { etanercept }\end{array}$ & $\begin{array}{l}3 \text { Months after beginning } \\
\text { etanercept }\end{array}$ \\
\hline \multicolumn{4}{|l|}{ Treatment (daily) } \\
\hline \multirow[t]{3}{*}{ Antiphlogistic } & \multirow{4}{*}{$\begin{array}{l}\text { Diclofenac } 2 \times 50 \mathrm{mg} \\
\text { Methylprednisolone } 16 \mathrm{mg} \\
\text { Colchicine } 4-6 \mathrm{mg} \\
\text { Flupirtine maleate } 200 \mathrm{mg} \\
\text { Fentanyl } 50 \mu \mathrm{g} / \mathrm{h}\end{array}$} & \multirow{4}{*}{$\begin{array}{l}\text { Methylprednisolone } 4 \mathrm{mg} \\
\text { Colchicine (if necessary) } \\
\text { Fentanyl } 20 \mu \mathrm{g} / \mathrm{h}\end{array}$} & \multirow{4}{*}{ Methylprednisolone $4 \mathrm{mg}$} \\
\hline & & & \\
\hline & & & \\
\hline Analgesic & & & \\
\hline Antihyperuricaemic & Urine alkaliser (Blemaren) & $\begin{array}{l}\text { Urine alkaliser (Blemaren) } \\
\text { Probenecid } 2 \mathrm{~g}\end{array}$ & $\begin{array}{l}\text { Urine alkaliser (Blemaren) } \\
\text { Probenecid } 3 \mathrm{~g}\end{array}$ \\
\hline \multicolumn{4}{|l|}{ Laboratory findings } \\
\hline $\mathrm{ESR}(\mathrm{mm} / 1 \mathrm{st} \mathrm{h})$ & 55 & 6 & 6 \\
\hline $\mathrm{CRP}(\mathrm{mg} / \mathrm{l})$ & 61.0 & 6.1 & $<5.0$ \\
\hline WBC $\left(\times 10^{9} / \mathrm{I}\right)$ & 9.4 & 7.4 & 5.3 \\
\hline Serum uric acid ( $\mu \mathrm{mol} / \mathrm{l})$ & 580 & 580 & 560 \\
\hline \multicolumn{4}{|l|}{ Clinical findings } \\
\hline Gouty attacks per week & $3-4$ & 1 & $1 /$ month \\
\hline Number of painful joints & 12 & 4 & 2 \\
\hline
\end{tabular}

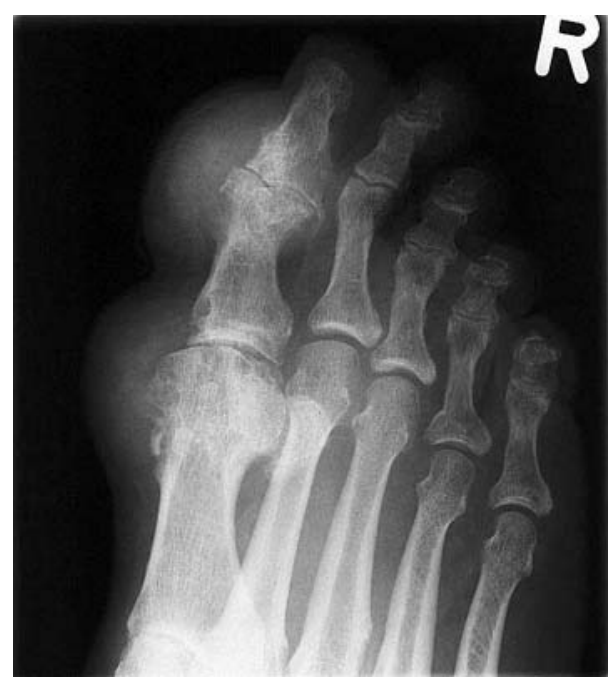

Figure 2 Radiographs of the right foot showing multiple cysts, amorphous calcifications, and spikes of urate crystals in soft tissue, and destruction and erosions of bone and cartilage.

\section{DISCUSSION}

Effective treatment exists to prevent the complications of symptomatic hyperuricaemia. However, severe gouty arthritis together with tophaceous manifestations are rarely seen. In most cases standard treatment with colchicine, non-steroidal anti-inflammatory drugs, and moderate doses of glucocorticosteroids is sufficient to control the inflammation of gouty attacks. ${ }^{12}$ In our patient the conservative treatment of the gout, including opioids for analgesia, did not control the attacks. The use of etanercept produced a noticeable decrease in all the pathological clinical and laboratory findings (table 1).

TNF $\alpha$ plays an important part in different inflammatory diseases. Today, anti-TNF $\alpha$ is widely used in the treatment of different kinds of arthritis and primary vasculitis. ${ }^{3-6}$

Acute and chronic gouty arthritis is an inflammatory disease, in which activation of certain white blood cells occurs owing to the presence of a foreign substance-namely, urate crystals. The activation of monocytes and macrophages releases $\mathrm{TNF} \alpha$ into the synovial fluid. ${ }^{78}$ Increased concentrations of $\mathrm{TNF} \alpha$ are detectable in joints of gouty arthritis. $^{9}$ In certain cases, gout can mimic rheumatoid arthritis. ${ }^{10}$

We describe the first published case of severe, recurrent tophaceous gouty arthritis refractory to anti-inflammatory treatment in a patient who was subsequently treated successfully with a TNF $\alpha$ inhibitor. Of particular interest is the possibility of maintaining antihyperuricaemic treatment during the antiphlogistic protection of etanercept, especially as there is a massive excavation of uric acid from the depots owing to the antihyperuricaemic treatment.

\section{Authors' affiliations}

A K Tausche, K Richter, A Grässler, S Hänsel, B Roch, H E Schröder, Section of Internal Medicine, Department of Rheumatology, University Clinic Carl Gustar Carus, Dresden University of Technology, Fetscherstrasse 74, D- 01307 Dresden, Germany

Correspondence to: Dr A K Tausche; anne-kathrin.tausche@ mailbox.tu-dresden.de

Accepted 1 December 2003

\section{REFERENCES}

1 Lange U, Schumann C, Schmidt KL. Current aspects of colchicine therapy Classical indications and new therapeutic uses. Eur J Med Res 2001:6:150-60.

2 Groff GD, Franck WA, Raddatz DA. Systemic steroid therapy for acute gout: a clinical trial and review of the literature. Semin Arthritis Rheum 1990:19:329-36.

3 Moreland LW, Schiff MH, Baumgartner SW, Tindall EA, Fleischman RM, Bulpitt KJ, et al. Etanercept therapy in rheumatoid arthritis: a randomized controlled trial. Ann Intern Med 1999;130:478-86.

4 Mease PJ. Tumor necrosis factor (TNF) in psoriatic arthritis: pathophysiology and treatment with TNF inhibitors. Ann Rheum Dis 2002;61:298-304.

5 Lamprecht P, Voswinkel J, Lilienthal T, Nolle B, Heller M, Gross WL, et al. Effectiveness of TNF- $\alpha$ blockade with infliximab in refractory Wegener's granulomatosis. Rheumatology (Oxford) 2002;41:1303-07.

6 Bartolucci P, Ramanoelina J, Cohen P, Mahr A, Godmer P, Le Hello C, et al. Efficacy of the anti-TNF- $\alpha$ antibody infliximab against refractory systemic vasculitides: an open pilot study on 10 patients. Rheumatology (Oxford) 2002;41:1126-32.

7 Agudelo CA, Wise CM. Gout: diagnosis, pathogenesis, and clinical manifestations. Curr Opin Rheumatol 2001;13:234-9.

8 LaDuca JR, Gaspari AA. Targeting tumor necrosis factor alpha. New drugs used to modulate inflammatory diseases. Dermatol Clin 2001;19:617-35.

9 Yagnik DR, Hillyer P, Marshall D, Smythe CD, Krausz T, Haskard DO, et al. Noninflammatory phagocytosis of monosodium urate monohydrate crystals by mouse macrophages. Implications for the control of joint inflammation in gout. Arthritis Rheum 2000;43:1779-89.

10 Schapira D, Stahl S, Izhak OB, Balbir-Gurman A, Nahir AM. Chronic tophaceous gouty arthritis mimicking rheumatoid arthritis. Semin Arthritis Rheum 1999;29:56-3. 


\section{Two young girls with pyogenic sacroiliitis}

\section{S W Kadir, M E C Jeurissen, M J A M Franssen}

Ann Rheum Dis 2004;63:1353-1354. doi: 10.1136/ard.2003.010959

$\mathrm{P}$ yogenic sacroiliitis is a rare condition with often vague symptoms mimicking common conditions such as protruded disk, muscular strain, or visceral pain. Therefore the diagnosis is often missed or delayed. In 1986, Cohn and Schoetz reviewed patients with pyogenic sacroiliitis. ${ }^{1}$ In $12.6 \%$ of these cases sacroiliitis mimicked the acute abdomen. In $40-60 \%$ fever and a raised erythrocyte sedimentation rate were present. Blood cultures were positive in $60 \%$. Magnetic resonance imaging and computer tomography can be helpful, but especially when blood cultures are negative, joint aspiration can be crucial for establishing the diagnosis. We present two cases of infectious sacroiliitis.

\section{CASE REPORTS}

\section{Patient 1}

A 19 year old woman was admitted to hospital with a 4 day history of pain in the right hip and buttock, and fever. Walking was difficult and transfers were impossible to make. Recently she had scratched the skin of her head causing some wounds. Monthly she used plugs during her menstruation. There were no abdominal complaints. She neither smoked nor used alcohol. Her medical history was unremarkable.

Examination showed a sick woman, with a temperature of $40.8^{\circ} \mathrm{C}$ and normal blood pressure. A general internal examination was normal. The right sacroiliac joint showed tenderness on pelvic compression without further limitations. The erythrocyte sedimentation rate was $40 \mathrm{~mm} / \mathrm{lst} \mathrm{h}$, $\mathrm{C}$ reactive protein $240 \mathrm{mg} / \mathrm{l}$, white blood cell count $8.4 \times 10^{9} / 1$. Plain $x$ ray examinations of chest, hip, and pelvis and ultrasonography of the hip were normal. Bone scan showed an increased uptake in the right sacroiliac joint. Magnetic resonance imaging demonstrated sacroiliitis of that joint. Four blood cultures disclosed Staphylococcus aureus. Treatment was started with 2 weeks' intravenous flucloxacillin $12 \mathrm{~g}$ daily, followed by an oral 2 week course $2 \mathrm{~g}$ daily. Mobility improved and she was discharged after 3 weeks. Follow up radiography showed sclerosis of the right sacroiliac joint. A year later she was still free of complaints.

\section{Patient 2}

A previously healthy 14 year old girl presented with acute, severe pain in the buttock radiating to the right leg and a temperature of $38^{\circ} \mathrm{C}$. Three weeks before admission her whole family was on holiday in Kenya, where they all experienced a short period of diarrhoea. It resolved completely in a few days. In Kenya she had used both milk and yoghurt, but no eggs. On holiday she had used plugs. There were no injuries or infections. Examination disclosed tenderness of the right sacroiliac joint and buttock.

A stress test of that joint was positive. Further physical examination was normal. Bearing weight on the right leg was impossible. The erythrocyte sedimentation rate was $77 \mathrm{~mm} /$ lst $\mathrm{h}, \mathrm{C}$ reactive protein $131 \mathrm{mg} / \mathrm{l}$, white blood cell count $12.4 \times 10^{9} /$ l. Plain $x$ ray examinations of chest, pelvis, and lumbar spine and ultrasonography of the hips were normal. Magnetic resonance imaging showed right sided sacroiliitis (fig 1). Blood cultures were negative, but cultures of stool and synovial fluid (after computed tomography guided punction) disclosed Salmonella group D.

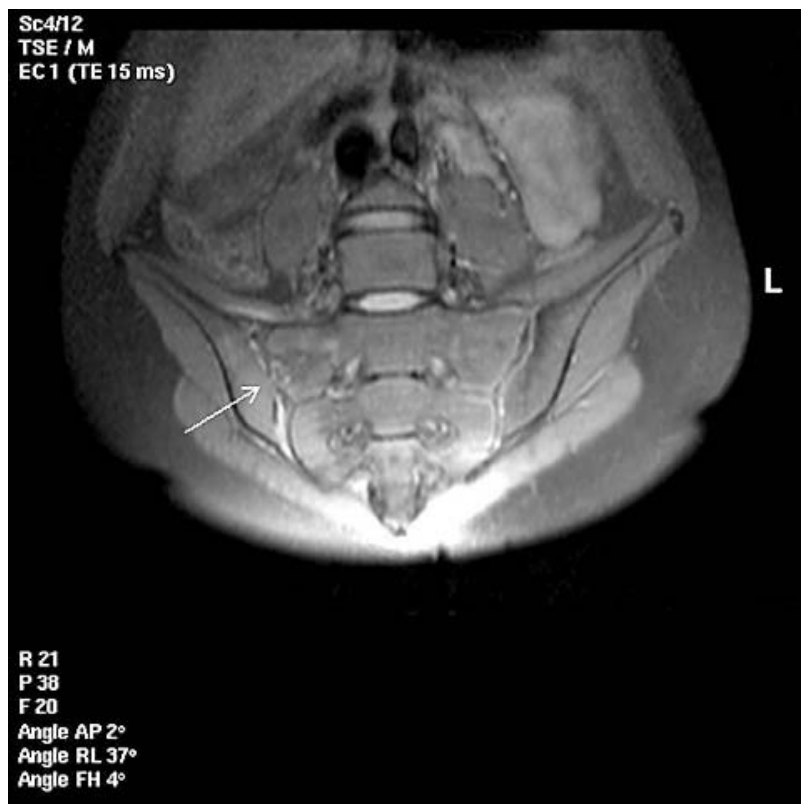

Figure $1 \mathrm{~T}_{2}$ sequence magnetic resonance imaging showing sacroiliitis of the right sacroiliac joint.

Treatment was started intravenously with ciprofloxacin $200 \mathrm{mg}$ twice a day for 10 days. Pain decreased and mobility improved. She was discharged after 10 days and continued oral ciprofloxacin $500 \mathrm{mg}$ twice a day for 3 weeks. Three months after presentation she was mobile without pain. A follow up pelvic $x$ ray examination showed erosive changes and sclerosis of the right sacroiliac joint.

\section{DISCUSSION}

Pyogenic sacroiliitis is rare, especially if caused by Salmonella. A review pointed to Staphylococcus aureus as the leading causative organism. Only 16 of the 200 cases were due to Salmonella. ${ }^{2}$ In brucellosis the sacroiliac joint was the most commonly affected osteoarticular site. ${ }^{3}$ Pseudomonas species were often found in intravenous drug abusers. ${ }^{4}$ Tuberculosis has usually been an indolent cause. ${ }^{5}$ Sacroiliitis due to Streptococcus pneumoniae is uncommon. ${ }^{6}$ High suspicion of a pyogenic sacroiliitis requires joint aspiration in order to establish the causative organism even if blood cultures and conventional radiography are normal.

\section{Authors' affiliations}

S W Kadir, M E C Jeurissen, M J A M Franssen, Department of Rheumatology, Sint Maartenskliniek Nijmegen, Hengstdal 3, $6522 \mathrm{JV}$ Nijmegen, The Netherlands

Correspondence to: Dr S W Kadir, Department of Rheumatology, Sint Maartenskliniek Nijmegen, Postbus 901 1, 6500 GM Nijmegen, The Netherlands; s.kadir@maartenskliniek.nl

Accepted 2 October 2003 


\section{REFERENCES}

1 Cohn SM, Schoetz DJ. Pyogenic sacroiliitis: another imitator of the acute abdomen. Surgery 1986;100:95-8.

2 Attarian DE, Durham NC. Septic sacroiliitis: the overlooked diagnosis. J South Orthop Assoc 2001; 10:57-60.

3 Ariza J, Pujol M, Valverde J, Nolla JM, Rufi G, Viladrich PF, et al. Brucellar sacroiliitis: findings in 63 episodes and current relevance. J Clin Inf Dis 1993;16:761-5.
4 Gordon G, Kabins SA. Pyogenic sacroiliitis. Am J Med 1980;69:50-6

5 Pouchot J, Vinceneux P, Barge J, Boussougant $Y$, Grossin M, Pierre J, et al. Tuberculosis of the sacroiliac joint: clinical features, outcome, and evaluation of closed needle biopsy in 11 consecutive cases. Am J Med 1988;84:622-8.

6 O'Brien CM, Darley ESR, Kelly AJ, Nelson IW. Septic sacroiliitis: an unusual causative organism in a rare condition. Int J Clin Pract 1998;52:206-7.

\section{Use of minocycline in rheumatoid arthritis: a district general hospital experience}

\section{E Suresh, I M Morris, P C Mattingly}

Ann Rheum Dis 2004;63:1354-1355. doi: 10.1136/ard.2003.017749

$\mathrm{D}$ ouble blind, randomised controlled trials have shown that minocycline is an effective disease modifying antirheumatic drug (DMARD) in rheumatoid arthritis (RA), compared with placebo ${ }^{1-4}$ or hydroxychloroquine. ${ }^{5}$ Minocycline was first used on the premise that RA may be caused by an infection but, subsequently, it was also shown to possess other properties such as matrix metalloproteinase inhibition and immunomodulation. Despite reported proof of its efficacy, most rheumatologists do not favour the use of minocycline in RA, possibly owing to availability of other "standard" DMARDs.

We performed a retrospective review of the case notes of 28 patients with RA who were prescribed minocycline. Treatment with minocycline in these patients began before the widespread availability of biological agents. Our aim was to assess the efficacy and safety of this drug in our hands compared with published trials. Our patients included 24 women and four men, aged between 43 and 80 years (mean 60 ). Their disease duration ranged from 2 to 48 years (mean 18). Rheumatoid factor status was known in 26 patients, of whom 21 were seropositive. Minocycline was used only after at least two to eight DMARDs (mean five drugs) had failed. None of these patients were receiving concomitant treatment with other DMARDs at the time of starting minocycline. We used minocycline in a dose of $100 \mathrm{mg}$ twice daily.

As this was a retrospective review of case notes, improvement in disease activity could only be assessed from the information in clinic letters. Clinical improvement was assessed by factors such as improvement in joint pain and swelling, duration of early morning stiffness, function, physician's global assessments, and general wellbeing of the patient, while improvement in laboratory measures was assessed by change in erythrocyte sedimentation rate (ESR) and haemoglobin.

In the opinion of the rheumatologist the drug was considered effective in $10(36 \%)$ patients, of whom seven were still taking it at the time of performing this study. Three of these 10 patients had to stop taking minocycline because of side effects. Benefit was noted after a mean duration of 4 months (range 2-6) and was sustained for a mean duration of 14 months (range 8-24). Stopping treatment owing to a lack of efficacy occurred in only $7 / 28$ (25\%) patients and they had taken the drug for a mean duration of 6 months (range 3-11). No differences in disease duration, number of DMARDs tried before starting minocycline, or rheumatoid factor status were found between responders and non-responders (also including patients who stopped minocycline owing to toxicity, but had received the drug for at least 4 months).

There was documented improvement in clinical measures in all patients who responded. Laboratory data were available for 24 patients, of whom 18 had taken the drug for at least 4 months (eight responders, 10 non-responders). Among the eight responders, ESR values improved by more than $40 \mathrm{~mm} /$ lst $\mathrm{h}$ in four patients (reduced to $13,25,31$, and $31 \mathrm{~mm} / \mathrm{lst}$ h), while haemoglobin improved by more than $20 \mathrm{~g} / \mathrm{l}$ in two patients. We did not note any deterioration of ESR or haemoglobin values in any of the other responders. However, the ESR and haemoglobin values either remained the same or deteriorated in all non-responders save for one patient.

Thirteen $(46 \%)$ patients, including the three patients in whom the drug was considered effective, stopped taking the drug because of side effects. There were no serious or long term adverse effects. The side effects that were directly attributable to minocycline included dizziness (four patients), nausea (three patients), dizziness and nausea, allergic rash, and reversible grey pigmentation (one patient each). Three patients stopped the drug owing to problems not directly related to minocycline (atrial fibrillation, allergic skin rash to trimethoprim, and non-specific chest pain). The reason for stopping minocycline was not clear from the notes for one patient.

As far as we know, no one has reported their experience with the use of minocycline in patients with RA outside a research setting. If the fact that minocycline was only tried in our patients after they had failed to respond to other DMARDs is taken into account, it can be considered as a moderately efficacious drug. Studies in future should examine the role of minocycline in early RA either on its own or as part of combination DMARD treatment.

\section{Authors' affiliations}

E Suresh, Western General Hospital, Crewe Road, Edinburgh EH4 2XU, UK

I M Morris, P C Mattingly, Kettering General Hospital, Rothwell Road, Kettering NN16 8UZ, UK

Correspondence to: Dr E Suresh, Rheumatic Diseases Unit, Western General Hospital, Crewe Road, Edinburgh EH4 2XU, UK;

dr_esuresh@hotmail.com

Accepted 6 December 2003 


\section{REFERENCES}

1 Tilley BC, Alarcon GS, Heyse SP, Trentham DE, Neuner R, Kaplan DA, et al. Minocycline in rheumatoid arthritis: a 48 -week double blind, placebo controlled trial. MIRA trial group. Ann Intern Med 1995;122:81-9.

2 Kloppenburg M, Breedveld FC, Terwiel JP, Mallee C, Dijkmans BA. Arthritis Rheum 1994;37:629-36.

3 O'Dell JR, Haire CE, Palmer W, Drymalski W, Wees S, Blakely K, et al.

Treatment of early rheumatoid arthritis with minocycline or placebo: results of a randomised, double blind placebo-controlled trial. Arthritis Rheum 1997;40:842-8.

4 O'Dell JR, Paulsen G, Haire CE, Blakely K, Palmer W, Wees S, et al. Treatment of early seropositive rheumatoid arthritis with minocycline: fouryear follow up of a double blind, placebo controlled trial. Arthritis Rheum 1999;42:1691-5.

5 O'Dell JR, Blakely KW, Mallek JA, Eckhoff PJ, Leff RD, Wees SJ. Treatment of early seropositive rheumatoid arthritis: a two-year double blind comparison of minocycline and hydroxychloroquine. Arthritis Rheum 2001;44:2235-41.

\title{
Toxic myopathy induced by the ingestion of loquat leaf extract
}

\author{
W R Saliba, L H Goldstein, G S Habib, M S Elias
}

Ann Rheum Dis 2004;63:1355-1356. doi: 10.1136/ard.2003.016790

oquat (Eriobotrya japonica) belongs to the trees of the Rosaceae family. Loquat leaves are widely used in the - preparation of oriental herbal teas. In folk medicine, the loquat leaves are used against various skin diseases, cough, nausea, and itching.

Loquat leaves contain ursolic acid and oleanolic acid, which both have hypoglycaemic and antihyperlipidaemic effects in test animals. ${ }^{1-3}$

\section{CASE REPORT}

We present a patient with hypertriglyceridaemia, who after ingestion of loquat leaf extract had a remarkable decrease in triglycerides and an increase in high density lipoprotein (HDL). However, this benefit was accompanied by toxic myopathy, resembling the effect of HMG-CoA reductase inhibitors and fibric acid derivatives.

A 39 year old man was found to have a high fasting triglyceride level on routine blood testing. The total cholesterol level was normal, and the HDL cholesterol was low. $\mathrm{He}$ was otherwise healthy and smoked one packet of cigarettes a day for 5 years. He did not take any drugs, and denied habitual alcohol intake. The patient was advised to stop smoking, and he started a low fat and sugar diet.

Three months after this regimen his triglyceride level remained high $(9.38 \mathrm{mmol} / \mathrm{l})$, total cholesterol $4.30 \mathrm{mmol} / \mathrm{l}$, and HDL $0.80 \mathrm{mmol} / \mathrm{l}$. The patient was prescribed bezafibrate $400 \mathrm{mg}$ daily. After 3 months on this regimen, the triglyceride level diminished to $3.88 \mathrm{mmol} / \mathrm{l}$, but the creatine kinase (CK) was $1400 \mathrm{IU} / \mathrm{l}$ (6 months earlier the CK level was normal). The man had not reported myalgia; he denied fall or any trauma within the past weeks. He also denied intramuscular drug injection and strenuous exercise. Bezafibrate was stopped and the CK level returned to normal after 2 weeks.

During the following year the patient had blood tests every 2 months, the triglyceride level during this period ranged from 6.20 to $18.06 \mathrm{mmol} / \mathrm{l}$, the total cholesterol from 3.69 to $5.10 \mathrm{mmol} / \mathrm{l}$, the HDL from 0.80 to $1.05 \mathrm{mmol} / \mathrm{l}$, and the CK was normal. The man refused to take lipid lowering agents, and he decided to try herbal medicines.

He had heard that an extract of loquat leaves (obtained by boiling the leaves in water) would be effective for his problem. During the following 2 weeks he drank about 2 litres daily of this extract until he presented with severe myalgia, particularly of the proximal muscles of the arms and legs. On examination he was afebrile, his body mass index was $22 \mathrm{~kg} / \mathrm{m}^{2}$. The proximal part of his limbs was tender, no erythema was detected. Blood tests showed: triglyceride $2.20 \mathrm{mmol} / \mathrm{l}$, total cholesterol $4.50 \mathrm{mmol} / \mathrm{l}$, HDL cholesterol $1.10 \mathrm{mmol} / \mathrm{l}$, CK $5950 \mathrm{IU} / \mathrm{l}$, lactic dehydrogenase $412 \mathrm{IU} / \mathrm{l}$, aspartate aminotransferase $113 \mathrm{IU} / \mathrm{l}$, alanine aminotransferase $85 \mathrm{IU} / \mathrm{l}$. A complete blood count, serum electrolytes, kidney, and thyroid function tests were normal. An electrocardiogram showed sinus rhythm without signs of ischaemia.

The patient was admitted and treated with intravenous fluids. On the third day the transaminases returned to normal, the CK level decreased to $1102 \mathrm{IU} / \mathrm{l}$, and the patient was discharged. Blood tests taken after 2 weeks showed a normal CK level and a triglyceride level of $4.14 \mathrm{mmol} / \mathrm{l}$. During the following 5 months the patient underwent three blood tests that showed a triglyceride level of 4.74$10.18 \mathrm{mmol} / \mathrm{l}$ and an HDL level of $0.85-1.00 \mathrm{mmol} / \mathrm{l}$; he decided to take the loquat leaf extract at reduced doses. Blood tests taken three weeks later showed; triglyceride $1.98 \mathrm{mmol} /$ l, HDL $1.15 \mathrm{mmol} / \mathrm{l}$, and CK $1330 \mathrm{IU} / \mathrm{l}$; the transaminases were normal.

\section{DISCUSSION}

The decreased triglyceride level, in addition to the myopathy, represented by myalgia and a rise in CK, in the absence of other apparent causes, strongly suggests that these effects are related to the ingestion of loquat leaf extract. This assumption is supported by the recurrence of the same effects after rechallenge by the patient himself. Whether the antihyperlipidaemic effect and toxic myopathy are related to the action of one or more constituents of the loquat leaves is not clear.

Only a minority of patients develop myopathy in response to lipid lowering agents, ${ }^{4-6}$ with an incidence ranging from 0.1 to $0.5 \%{ }^{4}$ There are strong indications that other (endocrine, metabolic, genetic) factors may have a role in the pathophysiology of the myopathy. ${ }^{4}$

In our patient the CK level increased significantly after 3 months' treatment with bezafibrate. This patient might have been particularly sensitive to this type of treatment, and may have a predisposing factor, probably genetic.

The pronounced difference of CK level on the two occasions after ingestion of loquat leaf extract, suggests that this extract has a dose dependent toxic effect. However, this toxic effect may occur only in predisposed patients as is the case for myopathy related to lipid lowering agents.

Ingestion of loquat leaves should be included in the differential diagnosis of myopathy. The potential effect of 
loquat leaves to lower triglyceride and increase HDL levels merits further investigation.

\author{
Authors' affiliations \\ W R Saliba, L H Goldstein, M S Elias, Department of Medicine C, \\ Hae'meK Medical Centre, affiliated to the Technion-Israel \\ Institute of Technology, Faculty of Medicine, Afula, 18101, \\ Israel \\ G S Habib, Department of Medicine B, Lady Davis Medical Centre, \\ affiliated to the Technion-Israel Institute of Technology, Faculty of \\ Medicine, Haifa, Israel
}

Correspondence to: DrW R Saliba; salibuss@yahoo.com

Accepted 6 December 2003

\section{REFERENCES}

1 Somova LO, Nadar A, Rammanan P, Shode FO. Cardiovascular, antihyperlipidemic and antioxidant effects of oleanolic acid and ursolic acid in experimental hypertension. Phytomedicine 2003;10:115-21.

2 Taniguchi S, Imayoshi Y, Kobayashi E, Takamatsu $Y$, Ito H, Hatano T, et al. production of bioactive triterpenes by Eriobotrya japonica call. Phytochemistry 2002;59:315-23.

3 De Tommasi N, De Simone F, Pizza C, Mahmood N, Moore PS, Conti C, et al. Constituents of Eriobotray japonica. A study of their antiviral properties. J Nat Prod 1992;55:1067-73.

4 Hodel C. Myopathy and rhabdomyolysis with lipid-lowering drugs. Toxicol Lett 2002; 128:159-68.

5 Gaist D, Rodriguez LA, Huerta C, Hallas J, Sindrup SH. Lipid-lowering drugs and risk of myopathy: a population-based follow-up study. Epidemiology $2001 ; 12: 565-9$.

6 Pasternak RC, Smith SC Jr, Bairey-Merz CN, Grundy SM, Cleeman J, Lenfant $\mathrm{C}$, et al. $\mathrm{ACC} / \mathrm{AHA} / \mathrm{NHLBI}$ clinical advisory on the use and safety of statins. J Am Coll Cardiol 2002;40:567-72.

\title{
Tumour necrosis factor receptor associated periodic syndrome (TRAPS) with central nervous system involvement
}

\author{
K Minden, E Aganna, M F McDermott, A Zink
}

Ann Rheum Dis 2004;63:1356-1357. doi: 10.1136/ard.2003.016006

$\mathrm{T}$ mour necrosis factor receptor associated periodic syndrome (TRAPS) is an autosomal dominant disorder resulting from mutations in the TNFRSFlA gene, characterised by recurrent attacks of fever, abdominal pain, severe myalgia, skin rashes, conjunctivitis, and/or periorbital oedema. ${ }^{23}$ These symptoms, which are partially explained by the unopposed action of tumour necrosis factor (TNF) owing to decreased soluble TNF receptor 1 (sTNFRSF1A) serum levels, ${ }^{4}$ can be alleviated by administration of etanercept, which is a TNFRSF1B (TNFR2) p75:Fc fusion protein. ${ }^{25}$

We describe a family in which one of three affected members with central nervous system (CNS) symptoms developed a demyelinating disorder suspected to be a feature of TRAPS.

\section{CASE REPORT}

A 20 year old white man and his 25 year old sister had complained about recurrent attacks of fever, abdominal and loin pain, severe myalgia, skin lesions, sore throat, conjunctivitis, and periorbital oedema since early childhood. These attacks had come at irregular intervals, lasted for 2 3 weeks, and were accompanied by greatly increased acute phase reactants. During childhood both patients had received long term steroid treatment, which partially alleviated the symptoms; in addition, they had been treated with multiple immunosuppressive drugs (for example, chlorambucil, azathioprine, methotrexate) without any detectable benefit, under the erroneous impression they had Still's disease.

The young man developed depressive symptoms without other signs of a neurological disease in his teens, while his sister experienced a neurological illness with dizziness and paraesthesia in her hands, feet, and around the umbilical area at the age of 22. At that time, conventional $\mathrm{T}_{2}$ weighted magnetic resonance imaging (MRI) of the brain disclosed multiple small hyperintense lesions (most were $<6 \mathrm{~mm}$ ), located in the supratentorial white matter, and some of which showed gadolinium enhancement on $\mathrm{T}_{1}$ weighted, spin echo sequences. The location of these lesions was not typical of multiple sclerosis; cerebrospinal fluid analysis showed pleocytosis and oligoclonal bands, while electroencephalography, visual and somatosensory evoked potentials, selective digital subtraction angiography, and a neurological examination were all normal.

The father of both siblings had also had periodic fevers in childhood, progressing in adulthood to intense localised muscle pain and profound stiffness, associated with depressive symptoms, memory impairment, and recurrent loss of sensation and power in his fingertips and hands. Both the clinical examination by a neurologist and the electromyography/neurography pointed to a myotonic disorder.

All three affected family members have a T50K mutation in exon 3 of the TNFRSFlA gene with associated low sTNFRSFlA levels; defective shedding of TNFRSFlA was demonstrated in the young man's peripheral blood mononuclear cells ${ }^{6}$ on FACS analysis. Given the severity of attacks in both siblings, treatment with etanercept was started, which dramatically improved both patients' wellbeing, with normalisation of laboratory values. An improvement in paraesthesia without further changes of the MRI findings occurred in the woman during the initial months of anti-TNF treatment. However, at month 20 of etanercept treatment unilateral optic neuritis developed and, compared with imaging performed 12 months previously, new demyelinating lesions were detected by fluid attenuated inversion recovery (FLAIR) MRI (fig 1). This clinical exacerbation occurred in what appeared to be the setting of a TRAPS flare, because fever, arthralgia, muscle stiffness, skin and eye lesions occurred concomitantly.

\section{DISCUSSION}

As increased TNF/TNFR signalling has a key role in TRAPS, ${ }^{4}$ and is also implicated in inflammatory demyelinating disease of the CNS, ${ }^{7}$ one may speculate that the CNS symptoms seen in the young woman are part of the TRAPS phenotype. This is supported by other reports of CNS symptoms in TRAPS, including a severe neurological illness in a woman with a T50M mutation, ${ }^{8}$ optic neuritis/papillitis in a woman with a C30R mutation," and behavioural changes in a man and his daughter with the R92Q variant. ${ }^{3}$ Whether the CNS symptoms in the woman's brother and father, however, were also 

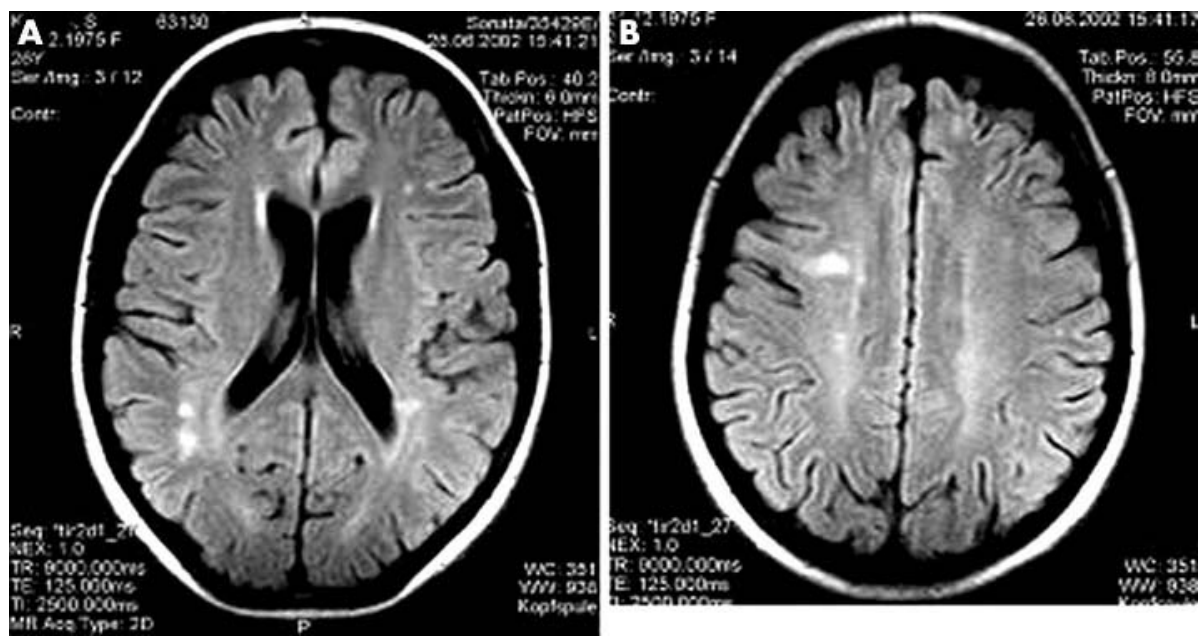

Figure 1 MRI scans of the brain of the young woman taken at the time of worsening disease 20 months after starting etanercept. Axial FLAIR images demonstrate multiple small hyperintense lesions in the supratentorial white matter. However, none of the lesions were enhanced after intravenous injection of gadolinium on conventional $\mathrm{T}_{1}$ weighted, spin echo imaging.

due to white matter disease is unknown, because imaging of the brain was not carried out in either of them and the presence of white matter disease was not proved conclusively by other examinations.

Etanercept has been shown to alleviate symptoms in about two thirds of patients with TRAPS, ${ }^{2}$ but it did not impede progression of the demyelinating disorder in this young woman. It remains unclear whether exacerbation of her neurological symptoms was an integral part of the disease flare or due to TNF antagonist treatment, as occasionally seen in patients with multiple sclerosis. ${ }^{10}$ Notably, another patient with TRAPS (T50M mutation) has also experienced paraesthesias and altered cognition while receiving etanercept (Hull K, personal communication).

Further research is necessary to verify whether CNS symptoms are part of the TRAPS phenotype or whether patients with TRAPS carry a particular risk of developing neurological complications owing to TNF antagonism. Meanwhile, clinicians should be aware of possible CNS involvement in TRAPS, with close monitoring of those patients receiving etanercept.

\section{Authors' affiliations}

K Minden, A Zink, German Rheumatism Research Centre Berlin, Epidemiology Unit, Germany

K Minden, Helios Klinikum, 2nd Children's Hospital Berlin-Buch, Rheumatology Unit, Germany

E Aganna, M F McDermott, Departments of Diabetes and Metabolic Medicine, Barts and the London, Queen Mary's School of Medicine and Dentistry, University of London, UK

Correspondence to: Dr K Minden, Deutsches RheumaForschungszentrum Berlin, Schumannstr 21/22, 10117 Berlin, Germany; minden@drfz.de
Accepted 19 November 2003

\section{REFERENCES}

1 McDermott MF, Aksentijevich I, Galon J, McDermott EM, Ogunkolade BW, Centola $M$, et al. Germline mutations in the extracellular domains of the $55 \mathrm{kDa}$ TNF receptor, TNFR1, define a family of dominantly inherited autoinflammatory syndromes. Cell 1999:97:133-44.

2 Hull KM, Drewe E, Aksentijevich I, Singh HK, Wong K, McDermott E, et al. The TNF receptor-associated periodic syndrome (TRAPS). Medicine (Baltimore) 2002;81:349-68.

3 Dodé $C$, André $M$, Bienvenu T, Hausfater $P$, Pêcheux $C$, Bienvenu J, et al. The enlarging clinical, genetic, and population spectrum of tumor necrosis factor receptor-associated periodic syndrome. Arthritis Rheum 2002;46:2181-8.

4 McDermott MF. TNF and TNFR biology in health and disease. Cell Mol Biol $2001 ; 47: 619-35$

5 Drewe E, McDermott EM, Powell PT, Isaacs JD, Powell RJ. Prospective study of anti-tumour necrosis factor receptor superfamily 1B fusion protein, and case study of anti-tumour necrosis factor receptor superfamily 1A fusion protein, in tumour necrosis factor receptor associated periodic syndrome (TRAPS): clinical and laboratory findings in a series of seven patients. Rheumatology (Oxford) 2003;42:235-9.

6 Aganna E, Hammond L, Hawkins PN, Aldea A, McKee SA, Ploos van Amstel HK, et al. Heterogeneity among patients with tumor necrosis factor receptor-associated periodic syndrome phenotypes. Arthritis Rheum 2003;48:2632-44.

7 Probert L, Eugster HP, Akassoglou K, Bauer J, Frei K, Lassmann H, et al. TNFR1 signalling is critical for the development of demyelination and the limitation of T-cell responses during immune-mediated CNS disease. Brain 2000;123:2005-19.

8 McDermott MF. Autosomal dominant recurrent fevers. Clinical and genetic aspects. Rev Rhum Engl Ed 1999;66:484-91.

9 Rösen-Wolff A, Kreth H-W, Hofmann S, Höhne K, Heubner G, Möbius D, et al. Periodic fever (TRAPS) caused by mutations in the TNF $\alpha$ receptor 1 (TNFRSF1A) gene of three German patients. Eur J Haematol 2001;67:105-9.

10 The Lenercept Multiple Sclerosis Study Group and the University of British Columbia MS/MRI Analysis Group. TNF neutralization in MS: results of a randomized, placebo-controlled multicenter study. Neurology 1999;53:457-65. 